\title{
New Section: 'What Is Your Diagnosis?'
}

The editors encourage the submission of interesting cases with unusual features, if possible with one or two suggestive figures. A short case description (a few lines) should be provided. The answer will appear in the same issue on a different page.

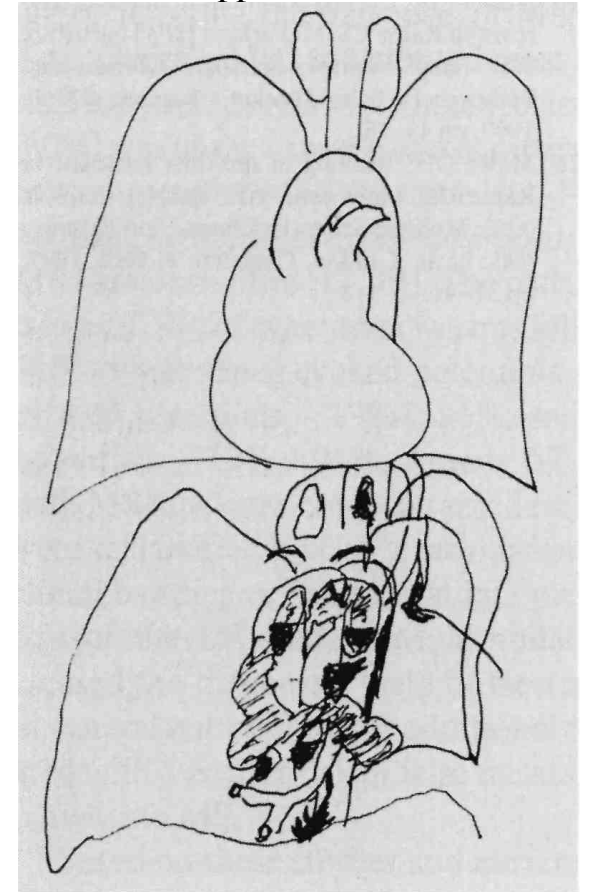

\section{Question}

\section{A Strange Case of Parkinsonism in a Gastroenterologist} I. Bogousslavsky, A. Carruzzo, Lausanne

A 74-year-old retired gastroenterologist was admitted to hospital for investigations of 'Parkinson's disease' evolving over a few years, with poor response to levodopa an bromocriptine, severe apathy and abulia, and urinary incontinence. On examination, he had hypomimia, without other abnormality on cranial nerves, including optic fundi. He had akinesia in the 4 limbs, with axial and limb rigidity, and a slight rest tremor in the left hand. Babinski sign and increased tendon reflexes were present on the right. Gait was festinating
with short steps. The patient showed a complete loss of initiative with perseverations, echowith short steps. The patient showed a complete loss of initiative with perseverations, echo-
lalia and bilateral grasp reflex. Since he was a physician, he was asked to draw the anatomical structure of the thoracic cage during a bedside neuropsychological testing: his drawing appears in the figure (top: model; bottom: patient's drawing). Then an investigation was performed (see answer on page 314 and compare it with your own diagnosis). 


\section{KARGEH}

E-Mail karger@karger.ch Fax + 4161306 12 34 http://www./.karger.ch
O 1997 S. Karger AG, Basel 0014-3022/97/10384-0258\$ 12.00/0

This article is also accessible online at: http://BioMedNet.com/karger 